\title{
Translation activities on oral translation and written translation
}

\author{
James P. Woang ${ }^{1}$
}

\section{ARTICLE INFO}

Received: 9 November 2020

Revised: 18 December 2020

Accepted: 27 January 2021

\section{KEYWORDS}

\section{liaison,}

lingual units, oral translation, translation activities, written translation.

\begin{abstract}
Translation activities and studies from one language to another must be carried out to understand the thoughts, ideas, culture, and knowledge of other nations who have different styles. Put translation activities can be divided into two types, namely oral translation or what is often referred to as oral translation and written translation, whereas translation studies are divided into two types, namely descriptive translation studies and translation theory studies. In the field of descriptive translation studies have two objects, namely the work of translation and the process of translation. Translation activities certainly require translation techniques or styles. Translation techniques are procedures or procedures for analyzing and classifying translation equivalents from source languages to target languages and can be used in a variety of lingual units. In translation activities, the use of techniques used by translators is not an important thing. The most important thing for a translator is the technique chosen can fulfill the purpose of the translation. Among the objectives of the translation, activity as a communication tool that connects the writer in the source language with the reader in the target language, and the translator as the mediator or the liaison of both.
\end{abstract}

(c) (i)

Copyright $\left({ }^{\circ} 2021\right.$ by The author(s). This is an open access article distributed under the terms of the Creative Commons Attribution (CC BY 4.0), which permits unrestricted use, distribution, and reproduction in any medium, as long as the original authors and source are cited. No permission is required from the authors or the publishers.

\footnotetext{
Correspondence:

Woang, J. P.

益 66123 Saarbrücken, Germany

woang@uni-saarland.de
}

${ }^{1} \sim$ Universität des Saarlandes, Saarbrucken, Germany 


\section{INTRODUCTION}

The correct use of translation techniques from the source language to the target language dramatically influences the quality of the translation, and this can be proven by the reader's understanding of the message, intent, or taste conveyed by the author in the source language. This study aims to classify the theory of translation used by translators and assess the quality of reading in the translation of noun phrases in the An-Nawawi Arbain Hadith. Translation of the Hadith is a vital thing to do in Indonesia, because Indonesia is a country with a majority Muslim population, so they should understand the teachings of their religion through the Koran and Al-Hadith. In understanding Al-Qur'an and AlHadith Indonesian people often experience difficulties, apart from the lack of mastery of Indonesian society over Arabic, also because Arabic is included in the Semit-Hamit language family which has one characteristic, namely producing vocabulary based on three consonants, which makes it possible to have children with different meanings [1].

\section{MATERIALS AND METHODS}

This research was conducted on the translation of Arba'in AnNawawi Hadith. To bridge this research, the methodological foundation that researchers use is a qualitative method. The qualitative method is a research method which is based on the philosophy of postpositivism, which is used to examine the condition of natural objects, producing descriptive data in the form of written or oral words where the researcher as the core means. Data collection techniques are carried out by triangulation (combined), data analysis used is inductive/qualitative, and the results of qualitative research are more inclined to meaning than generalization. In this study, researchers used a qualitative method with a descriptive approach. Data collection is done by collecting data related to the problem under study. This aims to be able to uncover the facts and find new data. Then researchers describe the problem by existing data to achieve the aims and objectives of the study [2][3]. The reason for the researchers to use descriptive qualitative methods is to find out the extent of the use of Molina and Albir translation techniques and their influence on the quality of the translation of the Arba' in An-Nawawi Hadith phrase.

The focus of this research is to analyze the results of the translation of the Arba'in An-Nawawi Hadith by Imam AnNawawi. The things that are assumed to be the object of study in the Arba'in An-Nawawi Hadith are describing the translation techniques used when translating Arba'in An-Nawawi's Hadith from Imam An-Nawawi from Arabic to Indonesian.
The data collection of this study uses triangulation techniques (combined); this is because this research is qualitative. While the data obtained is descriptive, in the form of written or oral data from many people. However, in this study, the data collected were only written data because this study was in the way of text research. The first step that the researcher did was to identify, listen to, and understand the translation of noun phrases in the Arba'in An-Nawawi Hadith translation, by using the method of looking.

The next step in the effort to collect data is to examine the use of the language used in translating noun phrases in the AnNawawi Arba'in Hadith. After that, the researcher tried to collect data relating to the translation techniques used by the interpreter of the Arba'in An-Nawawi Hadith. Next is to rerecord data that has been collected previously using the notetaking technique. This is done to make it easier for researchers to analyze data at the final stage. Then after the data is collected, researchers group according to specific criteria. In this study, the data obtained are intrinsically descriptive, which means that the information that has been taken is limited to the material or data that is used as the object of research.

Next, the authors analyzed the use of translation techniques and tested the quality of the translation of the target language by distributing questionnaires to several respondents. The criteria for respondents in this study are 1) Arabic Language and Literature Students Ahmad Dahlan University 5th semester, 2) Never took the theory of translation courses, 3) Mastering the target language (Indonesian). At the stage of exposure to data analysis, the authors write the results of the study in the form of reports that have previously been tested on the quality of the target language translation text with the source-language text [4].

The term "picture of the world" was put forward in the framework of physics in the late 19th and early 20th centuries. G. Hertz was one of the first to use this term. About national pictures of the world. Moscow, 1967, p. 208. in relation to the physical picture of the world, interpreted by him as a set of internal images of external objects, from which one can logically obtain information about the behavior of these objects. Internal images, or symbols, of external objects created by researchers, according to Hertz, should be such that "the logically necessary consequences of these ideas, in turn, were images of the naturally necessary consequences of the displayed objects.

The term "picture of the world" was also widely used by M. Plank M. Plank. The unity of the physical picture of the world. M.1989, p. 48., Understanding the physical picture of the world 
"image of the world" formed by physical science and reflecting. Real laws of nature M. Planck distinguished between the practical picture of the world and the scientific picture of the world. With the first, he linked a person's holistic view of the world around him, which he gradually develops based on his experiences. He interpreted the scientific picture of the world as a model of the real world in the absolute sense, independent of individuals and all human thinking [5].

\section{RESULTS AND DISCUSSIONS}

Although the sensory sensations caused by different objects in different people may not be the same, but the "picture of the world" of the world of things for all people is the same. When characterizing the picture of the world of V.I. Pustavalov V.I. Pustavalov. Picture of the world in human life. Moscow, 1998, p. 12. distinguishes between three important interrelated, but not identical phenomena: 1) a reality called the term "picture of the world"; 2) the concept "picture of the world", embodying the theoretical understanding of this reality; 3) the term "picture of the world". The phenomenon called the "picture of the world" is as ancient as man himself. The creation of the first pictures of the world in humans coincides in time with the process of anthropogenesis. Nevertheless, the reality called by the term "picture of the world" has become the subject of scientific and philosophical consideration only recently. The concept of a picture of the world is currently at the stage of its formation: the first attempts are being made to construct its detailed definition and to reveal its meaning; the questions of how it is reasonable to theoretically delimit the picture of the world from related phenomena, how to categorically characterize and identify the properties and forms of its existence are discussed.

Within the framework of linguistics, it has been suggested that the model of the world can be described as a set of basic semantic oppositions that are universal for the peoples of the world. For example, Viach. Ivanov and V.N. Toporov1 used the following semantic oppositions: white - black, immortality - death, close - distant, boiled - raw, vertical - horizontal, top bottom, summer - winter, visible - invisible, day - night, life death, red - black, sky - earth, happiness - misfortune, man non-human. Model of the world A.Ya. Gurevich 1. Viach. Ivanov and V.N. Toporov. Semantics of oppositions [6].

In the study of YKM, a special role is assigned to lexicology and, in particular, phraseology, since it is the phraseological units that "indirectly reflect the views of the people, the social system, and the ideology of their era. They reflect - as the light of the morning is reflected in a dew drop ". In the work of O.M. Kazakova on the study of the specifics of the Western and Russian mentality through the analysis of phraseological units (phraseological units in English and Russian), one can trace the presence of features characteristic of these two peoples. For example, a large number of English phraseological units emphasize ambition, the desire to be at the head, an active attitude to the world, the value of the present moment and individualism. While Russian phraseological units reflect such characteristic features of the people as hospitality, self-irony, unpredictability and irrationality.

V.A. Maslova notes that phraseological units, reflecting the long process of development of the culture of the people, are capable of fixing and transmitting from generation to generation cultural attitudes and stereotypes, standards and archetypes [Maslova 2001: 81]. Based on this statement, it is fair to speak about the existence of a phraseological picture of the world (FKM), which most clearly reveals the national and cultural specifics of various languages. FKM reflects not just the total knowledge of a person about the world order, but also the result of their figurative rethinking [7].

Therefore, the comparative study of the phraseology of different languages is of considerable interest for a wide range of researchers. Separate aspects of phraseological meaning, methods of their implementation in speech, structural and grammatical features and features of the component composition of phraseological units of individual languages are subjected to comparative study. Of interest are various aspects of paradigmatic and syntagmatic relations of phraseological units in both related and unrelated languages [8].

The categorical features of phraseological units include stability, reproducibility in speech, separate formality, the presence of at least one rethought component in its composition, and the integrity of meaning. As optional features of phraseological units, imagery / ugliness, predicative / nonpredicative are considered. The meaning of phraseological units is a special linguistic category and has a complex structure, which consists of subjectconceptual and connotative components. In each specific case, the first or second of them may prevail in the semantics of a phraseological unit, however, there are no clear boundaries between them. Phrasemics reflect the physical picture of the world, the socio-mental states of a person in this world and the person himself with his emotions, feelings, and inner world. In this sense, phraseological semantics is anthropocentric: a person is a bearer of culture, a certain system of knowledge, ideas, opinions about objective reality. This system in different sciences is described by different terms - "picture of the world", "model of the world", "image of the world", "conceptual system of the world", and, accordingly, is considered from different points of view. The appearance of this term in linguistics is due to research devoted to the problem of "man in the language and the language of man" in all its multidimensional and complexity [9]. 
The picture of the world and its individual fragments, represented by linguistic means, are a system, the unity and integrity of the elements of which arise in the process of its functioning. Each element in this system performs a specific function. Each language is an original system that imposes its own typos on the subconscious of its speakers and forms their picture of the world. The relationship between language and culture can be seen as a relationship between part and whole. Language can be perceived as a component of culture and its tool. However, language is autonomous in relation to culture as a whole, and it can be viewed as an autonomous semiotic system. From a linguistic and cultural point of view, language and culture are considered forms of consciousness that reflect a person's worldview, and are described in their synchronous interaction, since language serves as a means of accumulating and storing culturally significant information [10].

People live in a world of stereotypes that are imposed on us by culture. The range of mental stereotypes of the ethnos is known to each of its representatives. The images underlying phraseological units ensure the construction of a common and identical cultural space for native speakers, which is a condition for adequate communication between representatives of a given linguocultural community. Speakers of a certain language possess their own cultural code, thanks to which they interpret the meaning of phraseological units not only consciously, but also at the level of the unconscious. Thus, the language acts as a repeater of the culture of the people, helping to comprehend its customs and traditions and to reveal all the linguocultural specifics of each nation [11].

The study of the implementation of concepts in the linguistic picture of the world, or rather, in such a fragment as the phraseological picture of the world, is of undoubted interest. The interest is due to the fact that most phraseological units reflect history, life, culture, mentality, socio-economic life, the way of thinking of the people, and the peculiarities of its language. The study of the picture of the world presented in the phraseology of the Russian, English and French languages allows us to compare national stereotypes of behavior, traditions, cultural and national experience and life values of representatives of different societies.

The picture of the world is an ordered body of knowledge about reality, formed in the public (individual, group) consciousness [5, p. five]. It consists of many separate pictures of the world showing differences in the worldview of people. The subject of the picture of the world can be: 1) an individual (individual picture of the world); 2) a group of people (group picture of the world); 3) a separate people (national picture of the world); 4) humanity as a whole (general human picture of the world).
It is necessary to highlight the evaluative or axiological picture of the world. Each nation has its own idea of good and evil, beautiful and terrible, etc. The system of values characteristic of a particular culture is expressed in assessments and is part of the overall picture of the world. The way this system is organized is one of the main features of this language community. The evaluative attitude is usually considered as one of the types of modality that accompanies linguistic expressions. In contrast to the grammatical (that is, objectively temporal) modality, which is included in the descriptive (speaking about the world) content plan, the evaluative modality expresses the speaker's attitude to everything that is thought of as objective, independent of the subject [3, p. 29]. Evaluation is closely related to emotion and motivation, which are the main components of the semantics of nominative units. These concepts are of particular interest to language researchers at the present stage.

It should be borne in mind that the concept is a scientific model, with the help of which the object and plan of research, its scope, limitations, etc. are determined. It is necessary to establish how the concept should be investigated and what should be considered in language analysis to clarify its specifics. A concept in linguistics is considered as a definite concept, a unit of the mental level, which is stored in the memory of native speakers in a verbally designated form and is characterized by a set of cognitive and associative attitudes inherent in a particular language culture. Any concept contains many forms of expression in natural language, as well as in those spheres of human life that are predetermined by language and are unthinkable without it. The linguoculturological analysis of the basic concepts of the inner and outer world of a person makes it possible to clarify the degree of influence of language on the perception of a particular ethnic group, as well as how ethnic characteristics are "layered" on universal conceptual structures.

One of the key concepts of the worldview is the concept of "family", since it underlies the way of life of the compared societies. For Democrats, the concept of "family" is a family where good relations reign, where both parents have equal rights, raising children, where the spirit of love, care and mutual assistance reigns: marriage is honorable, wedlock is a padlock, man and wife make one fool; a chimney without smoke is like a couple without argument; mills and wives are ever wanting. Republican Americans have slightly different associations with this concept. For them, the "family" is a patriarchal family with strict principles of life, where there is a head of the family - a father who sets his own rules. Children in such a family are brought up in severity, and all family members perform certain duties: men were made of day but woman was made of man. 
In Russian phraseology, a woman usually occupies a more important place in the family than a man. She is the keeper of the hearth, and often the main person in it. This role of a woman in the family can be traced in the following Russian phraseological units: mama's son, honest mother !, to hell, show Kuzkin's mother, etc.

In France, the role of a leader in the family and in relations with children is played by the father, which is enshrined in phraseology: fils à papa (lit. "father's son"), de père en fils (lit. "from father to son"), en père de famille ("Like the father of the family"), contenter tout le monde et son père (lit. "to please everyone and your father"). If the domination of the husband in the family is assessed positively, then the power of the wife receives a sharply negative assessment. In phraseological units, this assessment is expressed using the images of "chicken" and "rooster": Eng. it is a sad house where the hen crows louder than the cock. They represent the metaphor of "a woman is a crowing hen."

In the popular minds of representatives of the English linguistic culture, the concept of "family" is associated with the creation of a nest and the life of birds: in English. lang .: it takes two birds to make a nest. This unit has the meaning "everyone must find his half", which is expressed using the token "two". Moreover, the role of both spouses in creating a family nest is emphasized.

The value of communication with close relatives is characteristic of the English, Russian and French linguocultures. For representatives of Russian society, the older generation is among the close relatives. For English and French speakers, the circle of close relatives is usually limited to members of the nuclear family (father, mother and their children).

It is noteworthy that the compared cultures reveal a potentially negative attitude towards distant relatives: second cousin twice removed, seventh water on jelly; le cousin a la mode de Bretagne. The British and French, due to their inherent individualism, are less focused on kinship than other ethnic groups; this fact explains the paucity of English and French phraseological units about relatives.

As a result of comparing the concept of "family" in three languages, it can be concluded that there are common and relevant characteristics. The universal characteristics for these languages are: similar composition of the field core; allocation of equivalents in the compared languages for all parts of speech. Specific features are: - the fragmentation of the nucleus and peripheral zones in English and Russian due to synonyms nominating a relationship, as well as their characteristic characteristics. These lexical units make it possible to more accurately determine the type of relationship and the position of an individual relative in a relationship.

The peripheral zone in French is expanding due to colloquial synonyms and lexemes of special meaning, while in English, along with colloquial synonyms, obsolete, vernacular and poetic lexical units are encountered. When comparing the axiological status of each parent in the child's value system, it is clear that the image of a mother who bears, nourishes, protects and cares is key and represents the "comfortable archetype". The sphere of its action is the unconscious in the human psyche, which is on the other side of rationality and can never be satisfied [6, p. 55]. The father, as the archetype of the parent, symbolizes the social order: "through this archetypal instance, the skills of cultural existence are acquired, nationally determined social laws are acquired" [6, p. 55]. The father acts as a relatively rigid cultural canon, the impact of which continues throughout life.

Most phraseological units about the family reflect the peculiarities of the mentality of the people, as well as the historical, ethnographic and cultural context. Thus, Russian, French, and English are not only different genetically, but also represent different linguistic pictures of the world. The analysis shows a certain relationship between the terms of kinship and parts of the family structure, which predetermines the associations that exist in the minds of the people. From the point of view of religious morality, marriage is significant in all three linguocultural societies. The basis of the biblical concept of the family is the thesis about the sanctity of marriage, presented in the phraseological saying: marriage is honorable. In the Russian language: marriages are made in heaven; in French: les mariages sont sacrés.

For over thirty years now, a number of new skills and subcompetences have emerged. In his manual for new translators, it mentions some of them: The new translator must in fact be ready [...to become] an information management expert, technician, terminologist, phraseologist, translator, adapter, proof-reader, reviser, quality control expert, post- editor, editor, graphic design expert and Web page designer, technical writer, Web site designer, Web page integrator, file manager, macrocommand writer and in some cases IT specialist, all rolled into one In this vein, writes: (...) evidence from the working world indicates that professional translating entails multiple forms of communication once considered as lying on the periphery of what was considered "translation proper": activities such as technical writing, editing, language consultancy and screen translation, for instance, are becoming core components of a translator's day-to-day practice. The implications of this process have been addressed by several authors [12]. They all seem to agree that there has been a shift towards large language service providers, full document production and automation.

Vol. 15 | No. 1 | 2021 | Pages: 28-38 
Similar trends are reported who observes that the translation market remains very fragmented. In 2009, the Editorial of the Applied Language Solutions, a Translation Services Company, published a long list of tasks performed by 'language service providers. These include interpretation, project management, terminology, language teaching, linguistics, cross-cultural training, diplomatic work, intelligence work, technical writing, DTP/page layout, web work, international work, stand-up comedian, bilingual editors, multimedia designers, research and information specialists, cultural assessors, multicultural software designers, software localizers, and terminologist [13].

All of the above-mentioned tasks involve collecting, processing, manipulating and validating language information. These requirements and the conditions of modern translation professional life, as well as the impact of globalization are challenges for teaching, as learners need to learn these new skills in order to be able to confront them, points out: "I believe that the most valued possession of a translator is his/her intellectual honesty (...) keep abreast of new developments affecting your business." It notes that these profound transformations in the profile of the translator are bringing the translation activity closer to that of monolingual text production. Some authors would even say that translation activities can no longer be called translation but rather "readeroriented writing" or "multilingual technical communication" [14], because the term "translation" cannot transmit the range of skills that are necessary, scholars of the GRELT research group working on Language for Translators, have underscored that the new translator's profile, as defined by market forces and social pressures makes it incumbent on training institutions to factor in the new profile into their training. The translator is not only, or not any more, a multilingual de-coder, but he/she is required to do, or to be prepared to do, rather more than just translate. It discusses the roles translators should be encouraged to take: If they are in a position to carry out other mediatory tasks, they should do so. This could involve things like actively preselecting information, advising on how a particular text should be translated, and suggesting how best to act in order to attain cooperation. A final consequence is of course that translators should be trained to carry out this wider range of mediatory tasks. More pointedly, they should be trained to know when not to translate.

This new trend is now being standardized with the appearance of new job titles, such as 'translator-editor'. These have pushed the job specifications - and thus the skills required for what was initially a translation position - one step further. Taking a market-oriented perspective, points to a growing tendency for employers to seek multi-skilled employees who are not only willing to learn and develop those skills, but who have already acquired them. In the translation market, this refers to translators who are ready to carry out more than just mechanical translation tasks and who have actually received training in that sense [15].

It provides an example of a new job description, that of translator-editor, a job particularly interesting because of the wide variety of competencies it envisages: Translate, revise, standardize and re-write public and internal documents such as reports, announcements, decisions, ministerial orders, brochures, press releases, memos, etc. for employees and managers of the agency. Coordinate the preparation of briefing notes for the Minister and, when the responsible person is absent, of ministerial and executive correspondence. Research, write, edit, French copy related to scientific technological exhibits and programs for visiting or virtual public. Produce small publications, write for websites, copyedit, translate English material with extensive scientific content into clear, interesting, understandable French copy and meet deadlines.

Consequently, if trainees are willing to enter the translation job market nowadays, they should expect to perform tasks varying from actual translating to writing summaries of a translated document, preparing material for publication or internal use, acting as an editor on source or translated texts and adapting the content of a text for a new audience. The students should be more specialized, more technical, but also be able to work within a wide range of subject areas. Teachers in translation teaching institutions are now faced with a new challenge, which terms an "unstable equilibrium", something really complex but necessary for the molding of multipurpose translators with skills in many fields and the capacity to adapt to the new expectations of the society [16].

As rightly points out, there has been a discernible move towards a more outcome-based approach, reflected in the Berlin Communique of September 2003 which encouraged Member States to elaborate a framework of comparable and compatible qualifications for their higher education systems. This framework seeks to describe qualifications in terms of learning outcomes, competences and profiles (Bologna Working Group on Qualifications Frameworks, 2004). This trend has impacted a keen interest internationally in identifying the competences that are required by career guidance $(\mathrm{CG})$ practitioners.

In Cameroon, the BMP system which is a step-child of the outcome or competency- based approaches was introduced into higher education in 2006. The intention is to express outcomes in the form of clear and precise 'competencies', so that (a) the needs of employment can be better communicated; (b) the goals of educational programmes can be re $\neg$ defined and communicated with greater precision; and (c) straightforward judgments can be made about the extent to which any particular competency has been attained: rather than designing 
curricula to meet assumed needs, representative occupational bodies identify 'occupational standards' which are clear and precise statements which describe what effective performance means in distinct occupational areas. The standards are then used to develop 'new' vocational qualifications and the assessment which underpins them; plus learning programmes which deliver the achievements identified in the standards [17].

In this vein, a professional translator needs to have sound knowledge about best practices in different situations and a variety of skills that will enable him/her to assess the job at hand and apply the best possible management and translation strategies to a particular situation. Much of the research effort in translation studies has been inspired by the need to describe and explain the phenomenon of translation itself and to establish what may be considered to be best professional practice. The competences required by a profession are usually determined by studying the behaviour and actions of the field's successful professionals. The competences described in these models are in turn used in translator and interpreter training. After all, educating new professionals is always linked to the everyday practice of the field and students are taught how to function in the professional arena.

In the specific domain of translation, A first priority [...] is the need to define more clearly the different sub-competences involved in the translation process, in order to try and identify a set of principles which could form the basis for a solid foundation for training in translation. Only then will it be possible to work on the interrelationship of these principles and finally to incorporate these into a programme designed to enable translators to achieve an overall (desired) level of translation competence (Schaffner and Adab ix). Translation practice requires a unique competence, perhaps a set of competences that comprise, of course, competence in the source and target languages.

Identifying the subset of fundamental competences related to translation competence helps to determine those to be prioritized in the language skills development class for translators, with the aim of bringing the student closer to the translation market exigencies with a body of knowledge acquired in advance. The translation profession has known a remarkable evolution that as quoted has this to say. The profession of translation (can be seen as) a special kind of ecosystem moving through time, modifying itself under the pressure of influences emanating from its socio-cultural environment, and evolving successfully from one form into another.

Seen in this new light as a Language Services provider, the translator should consistently excel in a number of specialties, and is generally regarded as one of the arbiters of very high level language consultancy. A weakness in any of these abilities will affect his performance adversely and have a negative impact on his employability.

As with all academic studies that have a vocational dimension, Translation Studies must balance the need to achieve full coverage of the discipline with the need to prepare graduates for the real professional world. 1.3 Translator Training Response To Current Trends In view of these changes, society today requires Higher Education to provide not only training, but also clear careers advice and a real possibility of preparing graduates for the transition to joining the labour force with relative ease and confidence, and in the best possible conditions. These wide-ranging, fast-paced changes in the translation job market clearly imply that a higher level of initial training is necessary for trainees to prepare them to function as active members of the profession when they gain employment. These changes therefore pose new challenges to translation pedagogy in terms of both content and methodology.

Over the past decade, new dynamics have emerged in each of the key domains of higher education, particularly in research and innovation. This paradigm shift has ushered in a more profession- and practice-oriented translator training and necessitated the inclusion of a wide variety of activities professional translators perform [18]. In this vein, translator training has undergone considerable changes since the beginning of the nineties, attempting to bridge the gap between the academic and professional worlds of translating.

Translator trainers, often professional translators themselves, have started to look at real translation situations, investigating what makes certain translations (and translators for that matter), more successful than others and incorporating their findings into their translation teaching approaches and methodologies. Translator education now recognizes the need for students to acquire a wide range of interpersonal skills and attitudes in addition to the purely technical skills ('translator competence').

As points out, it has become evident that successful economies are driven by innovation and knowledge. The skills required of workers have changed dramatically and rapidly over the last decades. It writes in her introduction of the Proceedings of the conference on 'Training the Language Services Provider for the New Millennium' in Porto , "Nowadays students need to be trained for the much wider variety of roles summed up in the phrase, 'language services provider.' She explains that in order to avoid the 'translation and interpreting' label: we opted for the expression 'Language services provider', in the hope that this would focus the need for training students for other functions, like those of revision, re $\neg$ writing and even writing the original texts, technical writing, terminology work, special language 
studies, dubbing, sub-titling, localization and the new technologies that have revolutionized the world of the more traditional translator and interpreter.

As early as 1992, recognized the importance of a broader, more multi-dimensional approach to training the translator not only as an intellectual polymath, but also as a multicultural expert. In fact, whether they are working as freelance translators, inhouse translators or part-time, translators have now moved from what calls the 'pure translator' to what he calls the translator with a lot of 'add-ons,' which he describes as the basic profile of what the market wants.

In developing countries, substantial reforms are taking place in tertiary education systems mainly aimed at encouraging institutions to be more responsive to the needs of society and the market economy. For example, the implementation of BMP in Cameroon since 2006 implies a change for higher education institutions, which have now to ensure that the learning outcomes of graduates fulfill the competency needs of the labour market. As a result, Higher Education must take into account teaching methodologies which bring training closer to the professional world, that is, Bringing Professional Practices into Translation Classrooms [19]. In translation, this implies providing students with the skills and competences required by practising translators in the workplace.

In this vein, translation teachers and researchers must show increasing interest in seeking alternatives to effete teaching methods - alternatives that will be better suited to the needs of students and employers against the backdrop of the radically changed market conditions over the past half century. In Towards a New World Order in Translation, he refers to the development of these competencies and skills as the process of translating the core abilities involved in effective practice into educationally useful elements. The translation market would benefit, as translators would be readier to adapt to emerging roles and more capable of sustaining quality and the argument for quality in the business. It opines that the demanding professional translation market expects would-be professionals to have a broad knowledge of the profession: Since translation is multidisciplinary, translator training programmes must instill not only proficient language command in both source- and target languages, but also, equally important, must bring together knowledge and skills that belong to different disciplines, such as documentation, terminology, desktop publishing, as well as some knowledge of specialized texts. Students must learn this so that they can ultimately thrive collectively as members of a profession.

Taking into consideration the growing importance of competency-based approaches, professional bodies, such as the ITI (Institute of Translation and Interpreting, UK), initiated programmes that facilitate such incorporation. The ITI brochure - Translation: getting it right (2003) - is a guide whose purpose is to educate all those taking part in the translation process. The brochure follows the example have set in describing the new roles that translators are expected to assume today. Consequently, it identifies the changing responsibilities and roles of translators, such as contributing actively to decisions made about the translatable content of the source text (ST), as well as the most appropriate translation approach and technique that should be employed [20].

This study adopts the empirical case study survey model in translation research. An outline of a model of the language skills translators need in order to work successfully as language services providers is developed through a case study opinion survey of 36 experienced service, freelance and corporate professional translators working in Cameroon. . Suggestions are made in the light of the model about curriculum design and teaching. The data collecting instrument used in this study is a questionnaire.

The informants for this part of the study are service translators working in the Cameroonian civil service and some freelance and corporate translators. The population was sampled using stratified and systematic sampling methods. Stratified sampling used variables such as gender and experience. Professionals who work both as freelance and in-house corporate translators from different cities were part of the sample.

Both quantitative and qualitative methods of data analysis have been used in this study. The questionnaires were administered by the researcher in face to face situations with the informants and others were sent and returned by mail. Various sources were used to know where and how to meet translators in the field such as directories, and visiting various offices to administer questionnaires to translators.

The professional translators' questionnaire elicits among other things, the various language-specific challenges in their career today brought about by changing market trends and how these could be factored in the language teaching course for translators. It is divided into five main components of professional experiences: professional translator's profile, former training, translation competence, materials and professional add-ons, experience, theoretical beliefs and recommendations. These instruments are used to validate the hypothesis on the pedagogical implication of the wider variety of linguistic roles imposed by changing market trends.

This section presents survey results on the pertinent issue of the profiles of translators in Cameroon and the major pedagogical problems involved: Is the profession changing as a result of the changes in society, and how? Which skills are essential for 
translators to adapt to the new scenarios? The results computed on table 1 reveal that the selection is representative because it covers all the major ministries including the Presidency of the Republic and the National Assembly. Furthermore, most of these translators also work for corporate bodies on a part time basis, and they also do some freelancing.

Further survey results from the demographic profile prove that $70 \%$ of professional translators in Cameroon are often asked to translate into their $\mathrm{B}$ languages provides a retrospective benchmark of professional standards against which development activities can be planned and prioritized. The section among other things seeks answers to questions relating to: Professionals' Assessment of language-specific communicative skills in professional translation; types of CAT tools used/mastered by professionals; list of texts translated by professionals in the field, and Language-specific activities that professionals perform as add-ons. Important components of communicative competence in translation include; cultural knowledge (44.4\%), communicative appropriateness (44.4\%) and textual competence $(44.4 \%)$. On the other hand, those skills which are not particularly prioritized are lexical and syntactic equivalences and oral fluency.

According to the results, the majority of professionals (95\%) are not familiar with CAT tools and translation software. Wordfast $(38 \%)$ and Trados $(36 \%)$ are the only CAT tools that most of them are acquainted with. Furthermore, none of these CAT tools were taught them in school [21]. A similar question was asked with regards to terminological tools mastered by professionals. Three popular terminology tools (Multi Term, Term Star, and Termium) were used to validate professionals' acquaintance with terminological software germane to the translation profession. The results of the survey show that like with CAT tools, 94\% of the professionals studied are not familiar with terminological tools. Very few, that is, $3 \%$ know about Multi Term and Termium.

This section of the study examines the materials, text-types and professional add-ons that professionals encounter in their workplace. This study analyses both perspectives and focuses on translational add-ons as a factor that is crucial for the design of a training programme that conforms to the current profile of professional translators. The statistics reveal that a majority of these text-types are often carried out in the field (33\%) while $26 \%$ of them come up very often. Secondly, regular texts activate both language and specialized domain competences requiring both written and oral expertise in language skills. The study also specifically wanted to know what language-specific activities professionals perform as add-ons to translation per se. A total of 21 activities were computed and are presented on table 5 below.
As the results of table 5 shows, professionals are increasingly involved in carrying out a lot of language-specific activities (add-ons) in the field. Out of a total number of 21 languagespecific activities computed, $14(66.6 \%)$ of these activities have become a frequent practice.

Holders of Bilingual degrees in English and French make up only $50 \%$ of the sampled population of professionals. The other $50 \%$ obtained degrees in various fields: history, Spanish, law, political sciences, sociology etc. This is an indication that, translation training has for long been opened to candidates from other professions other than language studies thereby confirming its interdisciplinary nature and the need to cater for candidates without a language background.

The sampled population is largely made up professionals with long standing experience who can provide studied information. However, the majority of

respondents $(88.90 \%)$ have never published in the field of translation. This means that a creative writing and research tradition has not been imbibed in most of the professionals. This explains why there is little information flow between professionals in the field and training institutions. Hence, Trainee translators are cut off from professional life experience. The introduction of academic and technical writing is very imperative for budding translators.

Results also reveal that close to $70 \%$ of professional translators in Cameroon are often asked to translate into their B languages. These results point to the importance attached to bidirectional translating in many contexts and which can only be aided by further language training in the second language in translator training programmes, particularly in Cameroon

Professionals consider the language courses more important for various reasons: more efficient use of language; the need to master the language before engaging in translation proper; helping those of them who did not do language studies to master the language; providing them with skills in writing etc. These results demonstrate that language problems in translator training are real for trainees, professionals and trainers.

A majority of sampled professionals (64\%) reveal that as students in their former schools, they applied a systematic study of grammar, stylistics and dictation to boost their language competence. Some $22(61 \%)$ respondents consulted grammar reference books, while some 20 others $(56 \%)$ read newspapers and journals. These results reveal that guided learners' autonomy can be an effective approach to language teaching in translator training.

The results also show that professionals are increasingly involved in carrying out a lot of language-specific activities 
(add-ons) in the field. This explains why translators are now referred to as language service providers. These new activities are fast impacting on the definition of new profiles for modern translation practice and should have implications for translator training. These results indicate that the translator's work goes beyond mere translating and the teaching of these new skills should ideally be factored into a language for translator training course within the framework of competency-based approaches.

Activities like writing of correspondences, scientific reports/minutes, terminology work, revision and editing, public relation work, language teaching, and supervision

of trainees have become a permanent occurrence. Most of these text-types are regularly carried on in the field (33\%) while $26 \%$ of them come up always. These regular texts activate both language and specialized domain competences requiring both written and oral expertise in language skills.

Furthermore, the majority of professionals (95\%) are not familiar with CAT tools and translation software like with CAT tools, and another $94 \%$ of the professionals are not familiar with terminological tools. Very few, that is, 3\% know about Multi Term and Termium. Conversely, a majority of the respon

\section{CONCLUSION}

Due to the fact that over the past ten years the importance of phraseological units in modern speech (oral and written) as a whole has increased tremendously, phraseological units turn out to be a mandatory part of the cultural minimum, which is necessary for adequate communication in any language. So, in the phraseology of different languages, there are mutually exclusive formulas of family interaction within one concept. However, on the whole, the analyzed views of all three ethnic groups on the family and marriage coincide in basic attitudes.

The standard profile of the translators in Cameroon is discussed using insights from the literature on market research and the competency-based approaches to translator training. Within this theoretical framework, the concept of translational language skills is deconstructed into 'separate language skills' and 'enhanced language skills.' Drawing from a survey of the Cameroonian translation market context, the study demonstrates that an explicit inclusion of workplace realities in Training would represent the progression of competency-based training required for successful participation in the workplace. The study posits that multi-competence is an added value of translation studies and that training programmes concentrating on core translation competence with parallel emphasis on market awareness and transferable skills would present significant advantages.

The study draws from the Flexible Professional in the Knowledge Society (REFLEX) analytical model by Seamus McGuinness and Peter J. Sloane (2009) which examines the labour market status of graduates after graduation and distinguishes their currents job, their vertical and horizontal mismatches and under skilling as well as a range of questions on the nature of work organisation and individual competences. A framework, informed by Second Language Teaching (SLT) is proposed with the aim of ameliorating the teaching of finelytuned language structures and skills to trainee translators.

\section{Conflict of Interest Statement}

The authors declare no conflicts of interest related to the material presented in this article.

\section{REFERENCES}

[1] Adda, G., Stüker, S., Adda-Decker, M., Ambouroue, O., Besacier, L., Blachon, D., ... \& Zerbian, S. (2016). Breaking the unwritten language barrier: The BULB project. Procedia Computer Science, 81, 8-14. https://doi.org/10.1016/j.procs.2016.04.023

[2] Blachon, D., Gauthier, E., Besacier, L., Kouarata, G. N., Adda-Decker, M., \& Rialland, A. (2016). Parallel speech collection for under-resourced language studies using the LIG-Aikuma mobile device app. Procedia Computer Science, 81, 61-66. https://doi.org/10.1016/j.procs.2016.04.030

[3] Borius, P. Y., Giussani, C., Draper, L., \& Roux, F. E. (2012). Sentence translation in proficient bilinguals: A direct electrostimulation brain mapping. Cortex, 48(5), 614-622. https://doi.org/10.1016/j.cortex.2011.01.011

[4] Calis, E., \& Dikilitas, K. (2012). The use of translation in EFL classes as L2 learning practice. Procedia-Social and Behavioral Sciences, 46, 5079-5084. https://doi.org/10.1016/j.sbspro.2012.06.389

[5] García, A. M. (2013). Brain activity during translation: A review of the neuroimaging evidence as a testing ground for clinically-based hypotheses. Journal of Neurolinguistics, 26(3), 370-383. https://doi.org/10.1016/j.jneuroling.2012.12.002

[6] House, J. (2006). Text and context in translation. Journal of pragmatics, 38(3), 338-358. https://doi.org/10.1016/j.pragma.2005.06.021

[7] Janssens, M., Lambert, J., \& Steyaert, C. (2004). Developing language strategies for international companies: The contribution of translation 
studies. Journal of World Business, 39(4), 414-430. https://doi.org/10.1016/j.jwb.2004.08.006

[8] Limpo, T., Alves, R. A., \& Connelly, V. (2017). Examining the transcription-writing link: Effects of handwriting fluency and spelling accuracy on writing performance via planning and translating in middle grades. Learning and Individual Differences, 53, 26-36. https://doi.org/10.1016/j.lindif.2016.11.004

[9] Malakoff, M. E. (1992). Translation ability: A natural bilingual and metalinguistic skill. In Advances in psychology (Vol. 83, pp. 515-529). North-Holland. https://doi.org/10.1016/S0166-4115(08)61514-9

[10] McDonald, J. L., \& Carpenter, P. A. (1981). Simultaneous translation: Idiom interpretation and parsing heuristics. Journal of Verbal Learning and Verbal Behavior, 20(2), 231-247. https://doi.org/10.1016/S00225371(81)90397-2

[11] O’Brien, S., Federici, F., Cadwell, P., Marlowe, J., \& Gerber, B. (2018). Language translation during disaster: A comparative analysis of five national approaches. International journal of disaster risk reduction, 31 , 627-636. https://doi.org/10.1016/j.ijdrr.2018.07.006

[12] Paradis, M., Goldblum, M. C., \& Abidi, R. (1982). Alternate antagonism with paradoxical translation behavior in two bilingual aphasic patients. Brain and language, 15(1), 55-69. https://doi.org/10.1016/0093934X(82)90046-3

[13] Pavuluri, M. N., O’Connor, M. M., Harral, E. M., Moss, M., \& Sweeney, J. A. (2006). Impact of neurocognitive function on academic difficulties in pediatric bipolar disorder: A clinical translation. Biological psychiatry, 60(9), 951-956. https://doi.org/10.1016/j.biopsych.2006.03.027

[14] Piekkari, R., Welch, D. E., Welch, L. S., Peltonen, J. P., \& Vesa, T. (2013). Translation behaviour: An exploratory study within a service multinational. International Business Review, 22(5), 771-783. https://doi.org/10.1016/j.ibusrev.2012.12.004

[15] Ruan, Y., Robinson, N. B., Khan, F. M., Hameed, I., Rahouma, M., Naik, A., ... \& Gaudino, M. (2020). The translation of surgical animal models to human clinical research: A cross-sectional study. International Journal of Surgery, 77, 25-29. https://doi.org/10.1016/j.ijsu.2020.03.023

[16] Ruiz, C., Paredes, N., Macizo, P., \& Bajo, M. T. (2008). Activation of lexical and syntactic target language properties in translation. Acta psychologica, 128(3), 490500. https://doi.org/10.1016/j.actpsy.2007.08.004

[17] Setton, R. (2006). Context in simultaneous interpretation. Journal of Pragmatics, 38(3), 374-389. https://doi.org/10.1016/j.pragma.2005.07.003
[18] Squires, A. (2009). Methodological challenges in crosslanguage qualitative research: A research review. International journal of nursing studies, 46(2), 277-287. https://doi.org/10.1016/j.ijnurstu.2008.08.006

[19] Squires, A., Aiken, L. H., Van den Heede, K., Sermeus, W., Bruyneel, L., Lindqvist, R., ... \& Matthews, A. (2013). A systematic survey instrument translation process for multi-country, comparative health workforce studies. International journal of nursing studies, 50(2), 264-273. https://doi.org/10.1016/j.ijnurstu.2012.02.015

[20] Uzawa, K. (1996). Second language learners' processes of L1 writing, L2 writing, and translation from L1 into L2. Journal of second language writing, 5(3), 271-294. https://doi.org/10.1016/S1060-3743(96)90005-3

[21] Wild, D., Eremenco, S., Mear, I., Martin, M., Houchin, C., Gawlicki, M., ... \& Molsen, E. (2009). Multinational trials - recommendations on the translations required, approaches to using the same language in different countries, and the approaches to support pooling the data: the ISPOR patient-reported outcomes translation and linguistic validation good research practices task force report. Value in Health, 12(4), 430-440. https://doi.org/10.1111/j.1524-4733.2008.00471.x 